\title{
Cómo descifrar sociológicamente una fotografía
}

Elementos teórico-metodológicos ${ }^{1}$

\author{
Hugo José Suárez² \\ Doctor en Sociología
}

"The camera is a wonderful mechanism. It will reproduce, exactly, what is going on inside of your head"

Saul Warkov ${ }^{3}$

\section{Resumen}

La fotografía es insumo para la sociología, muestra valoraciones, jerarquías, comunicaciones y compulsiones para la acción y contemplación. Connota y denota, eterniza un momento, producto de la decisión social de un colectivo. Sintetiza historiografía, información social, sistemas simbólicos, modelos culturales, imaginarios y sentidos; pero se debe saber descifrarlos.

1 El presente artículo será publicado próximamente en un libro colectivo sobre memoria y Ciencias Sociales editado por la Universidad Nacional Autónoma de México.

2 Doctor en Sociología por la Universidad Católica de Lovaina. Autor de "La transformación del sentido. Sociología de las estructuras simbólicas”, Ed. Muela del Diablo, La Paz, 2003, “¿Ser cristiano es ser de izquierda? La experiencia político-religiosa del cristianismo de liberación en Bolivia en los años 60", Ed. Muela del Diablo, La Paz, 2003. Profesor - investigador del Centro de Investigaciones en Ciencias Sociales de la Universidad de Guanajuato, México.

3 Citado por BECKER Howard, "Photography and Sociology", in Studies in the Anthropology of Visual Communications, N. 1, 1974. Versión recuperada de:

mhtml:file://C:IWINDOWSITEMP \ZZCT...Howard Becker - Photography and Sociology.mh 
El marco referencial para su análisis científico está en construcción. Durkheim, Weber, Bourdieu, Goffman, Barthes, Hiernaux son algunos autores que permiten iniciar este camino para la exploración de campos, estructuras y dinámicas socio-históricas, culturales, políticas, estéticas, éticas, morales o hedonistas.

\section{Palabras claves}

Sociología / connotación / denotación / análisis científico / sistemas simbólicos / modelos culturales / dinámicas sociohistóricas

\section{Abstract:}

Photography is an asset for sociology, it shows values, hierarchies, communications and compulsions for action and contemplation, it connotes and denotes; it eternizes a moment, a product of the social decision of a group. It synthesizes historiography, social information, symbolic systems, cultural models, made-up issues and our senses, but one must know how to decipher them. The referential framework for its scientific analysis is under construction. Durkheim, Weber, Bourdieu, Goffman, Barthes Hiernaux are some authors who initiate this approach for the exploration of cultural, political, aesthetic, ethical, moral, hedonistic, socio-historical fields, structures and dynamics.

\section{Key words}

Sociology / connotation / denotation / scientific analysis / symbolic systems / cultural models / socio-historical dynamics. 


\section{Introducción}

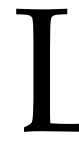

a fotografía y la sociología han recorrido un largo camino de la mano. De hecho, las dos comparten un período histórico y un territorio para su nacimiento (Europa del siglo XIX). Pero, lo más importante, comparten un mismo espíritu; a saber, introducirse en las dinámicas sociales". La fotografía, al ser, desde sus inicios, una "herramienta de exploración de la sociedad" ${ }^{5}$, es un insumo fundamental para la sociología.

Analizar la fotografía, desde la Ciencia Social, ha sido un desafío que varios autores han encarado con mayor o menor éxito. Podríamos recorrer distintos estudios e investigaciones con diversos enfoques que se han puesto en esta tarea, pero el objetivo de este artículo no es realizar un inventario de los análisis sobre la fotografía, sino la construcción de un marco teórico referencial y metodológico que nos permita leer científicamente este tipo de material.

Las preguntas son: ¿cómo utilizar la fotografía como un insumo para estudiar las mentalidades? ¿Qué elementos conceptuales nos ayudan a situar la foto como un material sociológicamente analizable? ¿Cuál es la dimensión sociológica de una fotografía? ¿Qué herramientas utilizar a la hora de analizar las imágenes? ¿Cuánto muestran y cuánto ocultan las fotos sobre dinámicas culturales de una sociedad?

4 BECKER Howard, "Photography and Sociology", in Studies in the Anthropology of Visual Communications, N. 1, 1974.

5 Ibidem. 
Luego, es evidente que la fotografía no es sólo un proceso químico de fijación de imágenes; es, antes que todo, un producto social que, bien observado, puede develar estructuras de sentido, valores, jerarquías, modelos culturales; en síntesis, una multiplicidad de saberes sociales ${ }^{6}$. Será la teoría, el método y la investigación empírica, en suma la sociología, la que podrá hacer de ella un insumo analítico; y es también ésta la que nos dirá cuáles son los aspectos esenciales de una imagen y cuáles no tienen valor. Queda claro, como sea, que el material fotográfico debe ser sometido a una lectura sociológica. Por tanto, antes de enfrentarse a documento empírico, hay que construir el objeto teórico de conocimiento.

En esa dirección -y siempre con el objetivo de construir herramientas teórico-metodológicas para el estudio de la fotografía-, el presente documento está dividido en dos secciones. En la primera parte, realizamos una reflexión conceptual, concentrados sobre todo en tres acercamientos distintos a la imagen: Bourdieu, Goffman y Barthes. En esta primera reflexión, tratamos de analizar cómo una fotografía devela modelos culturales y conlleva, en sí misma, una serie de imaginarios y sentidos. La segunda parte está dedicada a realizar un breve paseo por las herramientas para el análisis de la fotografía, acudiendo para ello tanto a nociones como campo social como a métodos de descripción estructural.

Todo este recorrido responde a la intención de tener elementos que permitan analizar determinadas producciones fotográficas en investigaciones empíricas que realizaremos en el futuro.

6 Véase GARRIGUES Emmanuel, L'écriture photographique. Essai de sociologie visuelle, L'Harmattan, Paris, 2000. 


\section{LA FOTOGRAFÍA ELEMENTOS CONCEPTUALES} Barthes.

Tres entradas a la fotografía: Bourdieu, Goffman y

Consideremos tres grandes autores para tomar de ellos lo que más sirva a nuestro propósito.

En su texto "La fotografía: Un arte intermedio", Bourdieu reflexiona sobre cómo y por qué la fotografía puede ser objeto de investigación sociológica. Su primera salida, quizás la más cómoda, será apelar a Weber cuando éste sugería que "el valor del objeto de investigación depende de los intereses del investigador"7. Sin embargo, el problema no se termina ahí. En su investigación, el autor constantemente apelará a argumentos que permitan, siguiendo la reflexión de las "Reglas del Método Sociológico" de Durkheim, ver la foto como un hecho social, es decir como "cosa".

Queda claro que, para Bourdieu, la foto es un hecho social. Para ello, la foto no debe ser vista en "sí misma y por sí misma" ${ }^{\prime \prime}$, sino como un producto resultado de un grupo que ocupa un lugar en la estructura social. Este autor se pregunta por qué la fotografía juega un rol en la vida social, y claramente responde que no es por el hecho de que su inversión económica y tecnológica haga de ella una práctica popular; esa sería una respuesta simple y que sólo respondería a la accesibilidad material. Lo que hace que la foto pueda ser vista como una "cosa" es que su uso responde a funciones y necesidades sociales predeterminadas: “la imagen fotográfi-

7 BOURDIEU Pierre (compilador), La Fotografía. Un arte intermedio, Ed. Nueva Imagen, México D.F., 1979, p. 15.

8 DURKHEIM Emile. Las reglas del método sociológico, Ed. Hispánicas S.A., México D.F., 1979.

9 BOURDIEU, Op. Cit., p. 42. 
ca, esa invención insólita que hubiera podido desconcertar o inquietar, se introduce muy temprano y se impone muy rápidamente (entre 1905 y 1914) porque viene a llenar funciones que preexistín a su aparición: la solemnización y la eternización de un tiempo importante de la vida colectiva" ${ }^{\prime 10}$.

Es a partir de esta premisa que el autor realizará su estudio, con aportes significativos que veremos luego.

Erving Goffman, en su texto "La ritualización de la feminidad", que es un estudio de la representación de la mujer en las publicidades inglesas, pretende identificar, las "estructuras de una organización única subyacente" que estarían en las fotos ${ }^{11}$. Para Goffman, el conjunto de publicidades manifiesta una "estructura subyacente común" o estereotipos que pueden ser descubiertos analíticamente. Las fotografías estarían, en este sentido, ofreciendo un "estilo de comportamiento ligado al sexo" que está siendo propuesto por el grupo productor de publicidades ${ }^{12}$. Su pregunta de trabajo es: “¿Cómo las fotografías pueden representar el mundo?"13.

Su premisa teórica es que las fotos permiten ver que, “detrás de una infinidad de variedades de configuraciones escénicas, se puede encontrar un idioma ritual único, y detrás de múltiples diferencias superficiales, un pequeña cantidad de formas estructurales"14. En el fondo, su trabajo consiste en intentar llegar a esas "formas estructurales" que manifiestan un "idioma ritual" absolutamente fundamental para la vida social de un determinado grupo. Estas "formas" son las que muestran las fotografías. En su trabajo, Goffman pretende analizar cómo las fotografías publicitarias "representan los sujetos humanos"15. En ellas intentará encontrar

10 Ibid, p. 39. Cursivas nuestras.

11 GOFFMAN Erving, "La ritualisation de la feminite", en Actes de la Recherche en Sciences Sociales, N. 14, Avril, 1977, p. 35.

12 Ibidem.

13 Ibid., p. 36.

14 Ibid., p. 38.

15 Ibid., p. 34. 


\section{los "puntos aparentemente comunes"16 y los estereotipos puestos en juego por un determinado colectivo.}

En sus resultados, el autor identifica una decena de ejes analíticos sobre la femineidad ${ }^{17}$ y descubre "'expresiones 'naturales' de la femineidad y de la masculinidad que se ven representadas en las imágenes publicitarias, y que son visualmente perceptibles"18.

Se trata de "unidades comportamentales de tipo ritual sobre una concepción ideal de los dos sexos y de sus relaciones estructurales", de la actitud de actores en una situación social ${ }^{19}$.

Por su parte, Roland Barthes, en su libro La cámara lúcida, está preocupado por saber qué es la fotografía “'en sí”,

16 Ibidem.

17 Los ejes analíticos resultado de su observación son:

i. Masculino/femenino. Un primer elemento es la separación sexual. Las fotos muestran una división jerárquica sexual, donde la mujer es subalterna a lo masculino. Las posturas muestran una superioridad del hombre frente a la mujer y cierta dependencia del primero respecto del segundo.

ii. El tacto. Hay una valorización de partes del cuerpo con ciertos atributos particulares. Las manos y su toque dejan ver cierta delicadeza y preciosidad corporal.

iii. La mujer oculta. Hay fotos que muestran a la mujer como alguien que se esconde, que no se deja ver, es misteriosa y se oculta de los hechos; se pone al borde de la situación siendo participante.

iv. Mujer lejana. Es aquella que observa con cierta sumisión, se ofrece a alguien (un hombre) para que la guíe.

v. La mujer sumisa. Una mujer en la cama, echada y durmiendo, muestra una similitud con un niño que duerme, como alguien que debe ser despertado o cuidado. La mujer sonriéndole a un hombre muestra una forma de relacionarse de un inferior con un superior.

vi. Juego de manos. El uso de las manos evoca una cierta disposición mental a alejarse, ingenuamente, de una determinada situación, cierta desorientación simpática, tímida y traviesa, que evoca protección por parte del otro. El cubrirse el rostro con las manos evoca la ritualización de un gesto asociado a la infancia, a los niños.

vii. Mujer dócil. Es el hombre el que ofrece, enseña, da algo a la mujer, desde saberes simples como la música hasta connotaciones eróticas.

viii. Mujer niña. La mujer asume un rol de subordinación frente al adulto o al padre.

ix. Mujer juego. Capacidad de mostrar a la mujer participando en un juego, con otros objetos como agua, nieve, etc. A la vez, hay mujer juguetona, con cierto toque cómico y actitudes semi-infantiles.

x. Felicidad de mujer. Las imágenes muestran que la mujer tiende a retirarse de la situación social y mirar más de lejos que como actor central.

18 Ibid., p. 50.

19 Ibidem. 
qué rasgo esencial la distinguía de la comunidad de imágenes" ${ }^{20}$. Su primer acercamiento es la clasificación en rubros (profesionales/ aficionados, paisajes/objetos/retratos, etc.). Pero eso no le muestra la esencia de la fotografía.

Para abordar el tema, la revisión bibliográfica que realiza no le es suficiente. Las reflexiones: son técnicas ("enfocan muy de cerca" el tema) o son históricas y sociológicas ("para observar el fenómeno global de la fotografía están, obligados a enfocar muy lejos" $)^{21}$. Afirma, irónicamente, alejándose tanto del acercamiento técnico como del sociológico: “¿Qué me importaban a mí las reglas de composición del paisaje fotográfico o, en el otro extremo, la Fotografía como rito familiar?"22. Esos dos lenguajes son, uno, el expresivo y, el otro, el crítico; pero ninguno le satisface.

Barthes enfoca el tema desde el sentimiento, desde su subjetividad. El punto de partida de su investigación, seleccionando fotos absolutamente arbitrarias, consiste en leer fotos que "estaba seguro que existían para mi"23. Su "corpus" es lo que a él le mueve e interesa, y desde ahí habla: "Heme, pues, a mí mismo como medida del 'saber' fotográfico" ${ }^{24}$. Su lectura es desde lo que "veo, siento, luego noto, miro y pienso" 25 .

Estas premisas teóricas lo llevarán a ver en la foto cuatro características fundamentales:

i. El principio de realidad. La foto reproduce "tal cual" una realidad. ${ }^{26}$

20 BARTHES Roland, La cámara lúcida. Nota sobre la fotografía, Ed. Paidós, Barcelona, 1998, p. 30.

21 Ibid., p. 35.

22 Ibidem.

23 Ibid., p. 37.

24 Ibid., p. 38.

25 Ibid., p. 58.

26 "La Fotografía que reproduce al infinito únicamente ha tenido lugar una sola vez: la Fotografía repite mecánicamente lo que nunca más podrá repetirse existencialmente". La foto muestra "lo Real en su expresión infatigable". La foto es la realidad "tal cual". Hay una brutalidad de realidad en la foto que hacen que esa sea su cualidad: "La fotografía dice: esto, esto es, eso está, es tal cual" (Ibid., p. 31-32). La foto es la evidencia, es una fatalidad de la realidad. 
ii. "Esto ha sido". La fotografía parecería decir "esto ha sido así", "esto ha estado ahí". La característica de la fotografía no es rememorar el pasado, "sino el testimonio de que lo que veo ha sido". ${ }^{27}$

iii. Objetivar al sujeto. La fotografía, particularmente en su función de retrato y por tanto la acción de posar, implica una experiencia de hacer del sujeto un objeto, una pieza de museo. ${ }^{28}$

iv. La foto como imagen de la muerte.

Luego de esta caracterización de la fotografía, el autor construye sus dos conceptos fundamentales: el studium y el punctum. El primero será más bien el contexto social que me permite "entender" una fotografía sin que llegue a afectarme afectivamente. El punctum, por el contrario, se trata de la "flecha que viene a punzarme", la "herida, el pinchazo, la marca hecha por un hecho puntiagudo" que me deja la foto ${ }^{29}$.

Con estos elementos, Barthes leerá, en su experiencia personal, las fotografías que a él le conmueven; $y$, a partir de ahí, realizará su análisis.

27 "La fotografía no dice (forzosamente) lo que ya no es, sino tan sólo y sin duda alguna lo que ha sido" (Ibid., p. 149). Por ejemplo, Barthes asegura que "por el hecho de tratarse de una fotografía, yo no podía negar que había estado allí (aunque no supiese dónde)" (Ibid., p. 150). Esto produce una especie de vértigo, pues es una memoria irrefutable. Por eso, dice Barthes "la fotografía jamás miente: o mejor, puede mentir sobre el sentido de la cosa, siendo tendenciosa por naturaleza, pero jamás podrá mentir sobre su existencia" (Ibid., p. 151). "La Fotografía es violenta no porque muestre violencias, sino porque cada vez llena a la fuerza la vista y porque en ella nada puede ser rechazado ni transformado" (Ibid., p. 159)

28 "La fotografía transformaba el sujeto en objeto e incluso, si cabe, en objeto de museo: para tomar los primeros retratos (hacia 1840) era necesario someter al sujeto a largas poses bajo una cristalera a pleno sol; devenir objeto hacía sufrir como una operación quirúrgica; se inventó entonces un aparato llamado apoya cabezas..." (Ibid., p. 45)

29 Ibid., p. 65. Studium no es exactamente "el estudio", "sino la aplicación a una cosa, el gusto por alguien, una suerte de dedicación general, ciertamente afanosa, pero sin agudeza especial. Por medio del studium, me intereso por muchas fotografías, ya sea porque las recibo como testimonios políticos, ya sea porque las saboreo como cuadros históricos buenos: pues es culturalmente (esta connotación está presente en el studium) como participo de los rostros, de los aspectos, de los gestos, de los decorados, de las 
De estos tres enfoques, es evidente que los autores parten de la intención de utilizar la fotografía desde un acercamiento de las Ciencias Sociales. Sin embargo, mientras que para Bourdieu lo importante son las funciones y usos sociales de la foto, y no le pone atención a la foto "en sí misma y por sí misma" (posición en parte compartida por Goffman, quien pretende, a través de las fotografías, ver las representaciones sociales), Barthes, quien toma distancia crítica de Bourdieu, se preguntará "qué me dicen las fotos a mí".

Es interesante notar que la pertinente lectura de Bourdieu no contempla el análisis de la imagen en sí misma, sino más bien su uso social; está preocupado por las prácticas y usos sociales y no por los contenidos de la fotografía. Barthes, en cambio, sí pone la interrogante explícitamente. Como lo veremos luego, se pregunta sobre el contenido mismo del mensaje fotográfico.

acciones" (cursiva nuestra Ibid., p. 64). Lo importante del studium es que evoca más bien al "entiendo" a partir de mi cultura o de elementos que me son familiares, pero no me seduce, no me convoca, no me duele ni provoca. Es la conciencia con la cual me acerco a la foto, y la leo así, la comprendo, la explico:

"El studium pertenece a la categoría del 'to like' y no del 'to love'; moviliza un deseo a medias, un querer a medias; es el mismo tipo de interés vago, liso, irresponsable, que se tiene por personas, espectáculos, vestidos o libros que encontramos 'bien' (Ibid., p. 66).

Para analizar el studium, hay que conocer las intenciones del fotógrafo, comprenderlas, explicar la relación entre creadores y consumidores, donde el que ve es consumidor. "Ocurre como si tuviese que leer en la Fotografía los mitos del fotógrafo, fraternizando con ellos, pero sin llegar a creerlos del todo" (Ibid., p. 67).

En el studium, la foto tiene funciones que hay que encontrar, que son "informar, representar, sorprender, hacer significar, dar ganas. En cuanto a mí, Spectator, las reconozco con más o menos placer: dedico a ello mi studium (que nunca es mi goce o mi dolor)" (Ibid., p. 67). La foto no produce ni gozo ni dolor, aunque se la disfrute.

El punctum es una herida provocada por la foto: "Ese segundo elemento que viene a perturbar el studium lo llamaré punctum; pues punctum es también: pinchazo, agujerito, pequeña mancha, pequeño corte, y también casualidad. El punctum de una foto es ese azar que en ella me despunta (pero que también me lastima, me punza)" (Ibid., p. 65).

El punctum es un detalle que atrae, puede ser una parte parcial de la foto, pero me convoca; es una pequeña parte que tiene una "fuerza de expansión" y que hace que sea yo interpelado. El punctum evoca nuestro pasado, nos interpela en lo personal, nos conmueve: "El punctum es, entonces, una especie de sutil más-allá-del-campo, como si la imagen lanzase el deseo más allá de lo que ella misma muestra” (Ibid., p. 109). 
El análisis de la imagen de Bourdieu es limitado, así como lo es el enfoque contextual de Barthes (es cierto que ninguno de ellos se demanda aquello como objetivo), por lo que, salvando las distancias, parece pertinente acudir a uno y otro autor a la hora de intentar explicar una producción fotográfica, o incluso para llegar a lo que Bourdieu denomina el ethos social que estaría implícito en la imagen. Paradójicamente, la pregunta sobre el contenido de la foto planteada por Barthes es la que nos permitirá llegar al desciframiento del ethos que propone Bourdieu. Es cierto que, para ello, es fundamental empezar con el análisis del campo cultural en el que se inscribe la fotografía; pero, el sentido mismo de la foto no lo podemos hacer inteligible desde ese análisis. Para ello, hay que dar un paso al frente e introducirse en el contenido de la foto en sí misma, lo que metodológicamente intentaremos hacer a partir del método de análisis estructural de contenido, como veremos adelante.

Definamos concretamente qué es nuestro objeto de conocimiento.

\section{Sistemas de sentido y fotografía}

Todo abordaje sociológico se inscribe en una corriente particular a partir de la cual mira la sociedad. El presente acercamiento a la fotografía está pensado desde la sociología de la cultura; particularmente, aquella corriente que se encargó de indagar sobre la construcción de los sistemas de sentido y modelos culturales ${ }^{30}$.

30 Véase HIERNAUX Jean Pierre, "Analyse structurale de contenus et modèles culturels. Application à des matériaux volumineux", in VV.AA., Pratiques et méthodes de la recherche en sciences sociales, Armand Colin, Paris, 1995; REMY Jean, VOYE Liliane, SERVAIS Emile, Produire ou reproduire. Une sociologie de la vie quotidienne, Ed. De Boeck, Bruxelles, 1991; SUAREZ Hugo José, La transformación del sentido. Sociología de las estructuras simbólicas, Ed. Muela del Diablo, La Paz, 2003; SUAREZ Hugo José, "La sociología cualitativa: el método de análisis estructural", in T'inkazos, N. 11, 2002. 
El objeto teórico de conocimiento son los sistemas simbólicos, entendidos como las estructuras subyacentes de sentido que indican valores, normas de comportamiento, orientaciones, jerarquías sociales, prioridades para la acción, etc. que, para un determinado grupo social, aparecen como "normales" o "evidentes". Remy sugiere que los sistemas simbólicos son el "conjunto de contenidos, más o menos explícitos, a partir de los cuales se sabe lo que está bien, lo que vale la pena, lo que aparece con cierto grado de normalidad" ${ }^{\prime \prime}$.

Los modelos culturales son construidos a partir de la experiencia del actor $y$, con cierto grado de abstracción, se puede llegar a modelos que respondan a colectivos similares: modelo de los cristianos revolucionarios ${ }^{32}$, modelo de grupos feministas, grupos rurales, etc. Los sistemas de sentido están instalados en la mente de las personas, ofreciéndoles "orientaciones a largo plazo, autónomas de la relación a la circunstancia" ${ }^{33}$ y sin que sea necesario racionalizarlos para acudir a ellos. Es decir, actúan pre-reflexivamente, más allá de todo intento de tomar una decisiones racionales (aunque también pueden ser racionales, lo importante es destacar que su capacidad está, precisamente, en que guían la acción sin pensarla).

Los modelos culturales abarcan, así, tanto el orden cognitivo (capacidad de percibir las cosas de una determinada manera, la "manera de ver las cosas") como el orden actorial (capacidad de guiar las acciones). Por tanto, son "guías (o constricciones) para la orientación

31 REMY Jean et VOYE Liliane, La ville et l'urbanisation. Modalités d'analyse sociologique, Ed. Duculot, Gembloux, 1974, p. 42.

32 Véase nuestro trabajo ¿Ser Cristiano es ser de izquierda? La transformación de simbólica de los cristianos en Bolivia en los años 60, Ed. Muela del Diablo, La Paz, 2003.

33 REMY Jean, "L'analyse structurale et la symbolique sociale", in Méthodes d'analyse de contenu et sociologie, Ed. Facultés Universitaires Saint-Louis, Bruxelles, 1990, p. 113. 
de los comportamientos" ${ }^{34}$. La capacidad fundamental de estas estructuras simbólicas está precisamente en, por un lado, "estructurar y orientar la percepción", y, por otro, "estructurar y orientar el actuar". Se trata entonces de sistemas que son "principios organizadores, a la vez, de la percepción y del comportamiento" 35 . Cómo los sistemas de sentido se producen, reproducen, transforman; cuál es su capacidad de movilización psicoafectiva; cómo se relacionan unos con otros, cuáles son las condiciones sociales para su funcionamiento, etc., son elementos que no trabajaremos en este artículo ${ }^{36}$. Lo importante es que, una vez que están ahí, su eficacia es fundamental para la vida social, y que los distintos grupos sociales poseen uno $\mathrm{u}$ otro modelo cultural que lo manifiesta de distintas maneras.

Si los sistemas de sentido son aquellas estructuras subyacentes instaladas en el cerebro de las personas que guían la percepción y el comportamiento, ¿cómo es que pueden ser "observables"? ¿Cómo analizarlas haciendo de ellas un material ciertamente sociológico?

Para responder a estas preguntas, es necesario aclarar que, más allá de la invisibilidad de los sistemas simbólicos, éstos quedan impresos en el paso del actor social por la sociedad. Es decir, podemos verlos tanto en los comportamientos como en los discursos escritos y orales, en las formas de vestir, en las elecciones profesionales, y así hasta el cansancio. Lo importante es, metodológicamente, realizar un corte y construir un corpus que permita analizar los contenidos. Así, se ha denominado "continente" aquellos discursos, textos, acciones, gestos, modos de vida, $\mathrm{y}$ otros que en bruto dejan ver algunos rastros de los sistemas de sentido. "Contenido", en cambio, será el sentido mismo de las cosas que se encuentra detrás de los textos,

34 HIERNAUX Jean Pierre, “Analyse structurale...”, p. 114.

35 Ibidem.

36 Para ello, véase nuestro trabajo La transformación del sentido...(2003, La Paz). 
discursos o acciones, es decir, las estructuras mismas que están en el fondo de la manifestación ${ }^{37}$.

Este recorrido conceptual es pertinente porque la fotografía es, precisamente, un magnífico "continente", a través del cual podemos ver, sin mucha dificultad y utilizando la metodología apropiada, cómo se manifiestan las representaciones culturales mayores que responden a determinados momentos de la historia con las respectivas visiones de mundo puestas en juego. Partimos, entonces, de la idea de que en un corpus analítico de fotografías, sometidas a un análisis, permitirá ver el sistema de sentido del grupo social responsable de su producción, o lo que en adelante denominaremos el mundo social fotografiado. La foto, por sus características sociales, económicas y técnicas, es un refugio de información que guarda en su seno fundamentales contenidos analíticos.

\section{La fotografía como manifestación cultural}

Acabamos de afirmar que la fotografía es, sobre todo, una "manifestación" que, por su extraordinaria capacidad de cortar la realidad en milésimas de segundo, puede cargar consigo una serie de contenidos culturales sujetos de ser analizados por la sociología. La fotografía permite ver cómo los valores, jerarquías, gustos y legitimidades de un grupo son aprehendidos no a través de canales institucionalizados y cuya función es la transmisión de valores, sino que por medios absolutamente "naturales". Diríamos que "naturalmente", sin que nadie "enseñe", uno sabe qué fotografiar, por lo que la fotografía se convierte en un ma-

37 HIERNAUX Jean Pierre, “Analyse structurale...”, p. 112. 
terial privilegiado para "observar cómo los valores de clase pueden transmitirse aun sin ninguna educación" ${ }^{38}$.

Bourdieu parte de un hecho fundamental: la cámara, por más que sea un aparato capaz de reproducir, sólo con un "clic", todo lo que se le ponga al frente, necesita, antes que nada, de una persona que realiza la toma y no de un robot que lo hace aleatoriamente. $\mathrm{Y}$ es esa persona quien en la foto invierte todo lo que es (valores, subjetividad, ethos, jerarquías, etc., en suma, lo que después entenderá por habitus):

“Aun cuando la producción de la imagen sea enteramente adjudicada al automatismo de la máquina, la toma sigue siendo una elección que involucra valores estéticos y éticos: si, de manera abstracta, la naturaleza y los progresos de la técnica fotográfica hacen que todas las cosas sean objetivamente "fotografiables", de hecho, en la infinidad teórica de las fotografías técnicamente posibles, cada grupo selecciona una gama finita $y$ definida de sujetos, géneros y composiciones" ${ }^{\prime 39}$.

Ya lo dice Bourdieu. De la infinidad de tomas posibles, es el fotógrafo el que selecciona, recorta la realidad, opta por algo, construye una relación entre objetos y acontecimientos sociales, y las plasma en la imagen:

“...La fotografía no puede quedar entregada a los azares de la fantasía individual y, por mediación del ethos - interiorización de regularidades objetivas y corrientes, el grupo subordina esta práctica a la regla colectiva, de modo que la fotografía más insignificante expresa, además de las intenciones explícitas de quien la ha tomado, el sistema de esquemas de percepción de pensamiento y de apreciación común a todo un grupo" ${ }^{40}$. 
La foto, nos dice Bourdieu, deja entrever los "sistemas de esquemas de percepción", o el "sistema de valores implícitos del grupo" ${ }^{41}$. Es decir, se trata de una manifestación que nos puede conducir hacia los esquemas de percepción más profundos: "ni natural ni creada deliberadamente, la necesidad de fotografías y de fotografiar, en realidad, no son sino el reflejo en la conciencia de los sujetos de la función social a la que sirve su práctica" ${ }^{42}$.

Todo el esfuerzo de Bourdieu gira alrededor de saber qué hace la gente con la foto, cómo la usa, cómo la aprecia, cuánto la usa, para qué. Poco entra en el contenido mismo de la foto, aunque sí advierte que hay una estrecha relación entre ethos de clase e imagen.

El ethos de clase es el "conjunto de valores que, sin alcanzar la explicitación sistemática, tiende a organizar la "conducta de la vida" de una clase social".

El aporte fundamental es, entonces, que hay que estudiar la fotografía a partir de los grupos a quienes pertenecen (y las producen) y las funciones que se les asigna:

"La estética que se expresa tanto en la práctica fotográfica como en los juicios sobre la fotografía, aparece como una dimensión del ethos, de manera que el análisis estético de la gran masa de obras fotográficas puede legítimamente reducirse, sin ser reductora, a la sociología de los grupos que las producen, de las funciones que les asignan y de las significaciones que les confieren, explícita y, sobre todo, implícitamente" ${ }^{\prime 3}$. 


\section{El campo de lo fotografiable}

Una primera idea es que "nada puede ser fotografiado fuera de lo que debe serlo" 44 . Ninguna foto es casual, sino que más bien responde a una lectura social, o una forma particular de leer lo social.

Existe, pues, un "campo de lo fotografiable" que no puede ser infinito, sino que está claramente (aunque no explícitamente) definido para el actor.

Se abre, así, un primer elemento analítico: ¿qué es fotografiable y qué no? ¿Por qué los grupos sociales seleccionan, cuidadosa y subjetivamente, algunos elementos que consideran pertinentes y otros los dejan de lado? ¿Qué es "digno de ser fotografiado, es decir, fijado, conservado, mostrado y admirado" ${ }^{45}$ ?

Estas preguntas le devuelven a la fotografía un estatuto fundamental para poder ser estudiada sociológicamente. El objetivo será comprender una fotografía sin importar su procedencia (fotografía profesional, popular, familiar, etc.), y, para ello, se debe no "solamente recuperar las significaciones que proclama, es decir, en cierta medida las intenciones explícitas de su autor, [se debe] también, descifrar el excedente de significación que traiciona, en la medida en que participa de la simbólica de una época, de una clase o de un grupo artístico" ${ }^{\prime 4}$.

Bourdieu pone énfasis en el hecho de que las condiciones objetivas en las cuales se inserta una clase son las que delimitan el escenario de lo posible, lo imposible, lo

44 Ibid., p. 44

45 Ibid., p. 23.

46 Ibidem. Bourdieu aquí hace un juego de palabras, proclama vs. traiciona, y las pone en cursivas. No es para menos, pues "proclamar" es enunciar racionalmente lo que la persona quiere decir, a través de una foto, de una actitud o un escrito, mientras que "traicionar" más bien evoca el hecho de que, más allá de la voluntad del propio actor, existen estructuras profundas que, incluso subjetivamente, están organizando y guiando sus opciones, acciones, actitudes. 
pertinente y lo que debe o no ser tomado en cuenta. En el caso de la fotografía, son pues estas "condiciones" las que definen las aspiraciones y exigencias (en su forma y contenido), que "excluyen la posibilidad de la aspiración a lo imposible" 47 . El "sistema de posibilidades y de imposibilidades objetivas", en este caso para la toma de una foto, estará influido por una u otra posición social, por las "condiciones de existencia diferentes" ${ }^{48}$ por las cuales cada uno tuvo que atravesar.

Esto implica un proceso previo de "interiorización de los límites", definidos tanto por las condiciones materiales y económicas como por la conciencia propia, ya "domesticada", que delimitan la posibilidad de lo posible, o lo que es posible para mí (como clase) y lo que está más bien destinado a otros.

La "conciencia de la imposibilidad y de la prohibición" ${ }^{49}$ sería el resultado de esta trayectoria social que conforman un ethos (en este caso fotográfico) que hace que alguien discierna entre una $u$ otra toma, valorizando algo, dejando de lado otra cosa y, en suma, construyendo su propia manera de ver las cosas a través de la foto.

En el caso propiamente de la foto, la lectura sociológica no debe limitarse a organizar temáticamente las fotografías, sino que se deben descifrar los inmensos contenidos profundos que cada imagen tiene consigo (y lo que evita o ignora), y que precisamente responden a un mundo social mucho más complejo, es decir, a un modelo cultural o sistemas de valores que no aparecen explícitamente sino que deben ser rastreados cuidadosamente.

Siendo éste el objeto teórico de estudio, veamos ahora los elementos metodológicos para analizar la fotografía. 


\section{HERRAMIENTAS PARA EL ANÁLISIS DE LA FOTOGRAFÍA}

En el apartado anterior, hemos realizado un recorrido conceptual para situar la fotografía como un objeto para las ciencias sociales. Corresponde ahora construir herramientas que permitan observar la foto con detenimiento y sacar de ella conclusiones sociológicas.

La pregunta de Barthes resulta pertinente, pues intenta comprender "¿cuál es el contenido del mensaje fotográfico? ¿Qué es lo que transmite la fotografía?"50. Esta interrogante impone penetrar en la complejidad de una fotografía que, para analizarla, exige múltiples enfoques y herramientas ${ }^{51}$.

Nuestro abordaje metodológico se concentra, precisamente, más en el contenido y sentido del mensaje fotográfico que en el uso social. Sin embargo, queda claro que la comprensión global de una fotografía, sólo se logra cuando se explican tanto elementos que tienen que ver con los usos sociales o las condiciones culturales de producción de una foto, cuanto aspectos estrictamente relacionados con contenido de la imagen.

Para hacer un análisis de la foto y llegar a sus contenidos más complejos, parece importante asumir distintas dimensiones analíticas. Primero hablaremos brevemente del campo cultural de producción de la foto, luego de las denotaciones, las connotaciones $y$, finalmente, las estructuras de sentido. Sólo una entrada multidimensional podrá colocar

50 BARTHES Roland, Lo obvio y lo obtuso, Imágenes, gestos, voces, Ed. Piados, Barcelona, 1995, p. 13.

51 Barthes propone que la fotografía es "objeto dotado de una autonomía estructural". Sin embargo, no se trata de una estructura aislada, por lo que "tan sólo después de agotar el estudio de cada una de las estructuras se estará en condiciones de comprender la manera en que se complementan estas" (Ibid, p. 12). 
a la fotografía en un lugar científico y no quedarse con ella como un artefacto simplemente descriptivo.

Hay que hacer notar que este abordaje pretende, como ya dijimos, utilizar herramientas metodológicas que sean capaces de exprimir de una imagen el contenido sociológicamente implícito. Una buena parte de los estudios de la imagen se quedan en la primera y segunda etapa, nuestra intención es, precisamente, llegar a los sentidos últimos de las fotografías.

\section{El campo cultural de la producción fotográfica}

La noción de campo proviene de la teoría de Bourdieu, pues, cuando lee la realidad, identifica espacios sociales con dinámicas semi-autónomas donde los agentes que están en su interior luchan, se enfrenta y compiten de acuerdo a la posición que ocupan en la estructura. Es en este campo de fuerzas que los actores se deben posesionar con respecto a los demás, y para ello utilizan sus distintos capitales ${ }^{52}$. Se trata de un espacio social dentro del cual funciona una serie intereses; los agentes pertenecientes al campo invierten sus capitales para tener un mejor posicionamiento. Hay algo en juego en el campo que hace que los miembros tengan interés en buscarlo y entrar en la competencia.

Concretamente, en el caso del análisis de la fotografía, se debe comenzar dibujando el campo fotográfico tanto en sus características fundamentales como en sus agentes principales; por ejemplo: fotógrafos, consumidores, mercado, tecnología, etc..

52 Véase BOURDIEU Pierre, Raison pratiques, sur la théorie de l'action, Ed. Seuil, Paris, 1994. 
Complementariamente, Barthes habla de tres categorías: el operator, que sería el fotógrafo propiamente dicho; el spectator que son quienes consumen las fotos (en libros, periódicos, álbumes, exposiciones y otros); y, finalmente, el spectrum, que es lo que es fotografiado, el objeto mismo ${ }^{53}$.

Para que se dé el producto final de la fotografía, entran en juego los elementos constitutivos y las coordenadas de situación. Los primeros serán de tres naturalezas: Asunto (tema elegido como por Ej.: la arquitectura, la gente, los niños, etc.), el fotógrafo (autor del registro, el responsable de la imagen); la tecnología (materiales y aspectos tecnológicos que le permiten al fotógrafo hacer su trabajo). Las coordenadas de situación serán el espacio geográfico donde ocurre la fotografía, y el tiempo cronológico (fecha, época, momento) en el que se realiza la foto ${ }^{54}$.

La combinación de estos distintos elementos es la que nos dará una u otra foto. Por tanto, todo análisis debe tomarlos en cuenta cruzando distintas variables históricas que permitan ver la foto como un producto social que responde a las necesidades en un campo cultural. Es al interior de este espacio social que el fotógrafo desplegará su modelo cultural ${ }^{55}$.

Hecho este análisis general del fotógrafo, su trayectoria, el campo en el cual se mueve y su obra, se debe pasar a la organización descriptiva de los elementos que portan una fotografía.

53 Este último término viene de la palabra "espectáculo" asumiendo la foto como "el retorno de lo muerto" (BARTHES, La cámara..., p. 39). En realidad toda la reflexión de Barthes se concentrará entre el spectator (él mismo) y el spectrum.

54 KOSSOY Boris, Fotografía e historia, Ed. La Marca, Buenos Aires, 2001, p. 31-32.

55 Véase BOURDIEU Pierre, Les règles de l'art. Genèse et structure du champ littéraire, Ed. Seuil, Paris, 1992; BOURDIEU Pierre y BOURDIEU Marie-Claire, Creencia artística y bienes simbólicos. Elementos para una sociología de la cultura, Ed. Aurelia Rivera, Buenos Aires, 2003; BECKER Howard, Art Worlds, Ed. University of California Press, London, 1982. 


\section{El análisis denotativo}

Para dar respuesta a las preguntas sobre el contenido de las imágenes, Barthes sugiere una distinción entre connotaciones y denotaciones. La foto, dice el autor, tiene dos mensajes: uno sin código (la realidad) y uno con código (el contenido y sentido de la imagen). La denotación es la cercanía con la realidad, una especie de "objetividad" y fidelidad de la imagen con respecto a la realidad; es la información "tal cual" aparece o la "realidad objetiva". Muchos estudios de la imagen, o sus usos en el sentido común, apelan precisamente al mensaje "sin código" de la foto, tomando las informaciones como un reflejo, más o menos fiel, de la realidad.

El análisis denotativo es, grosso modo, un inventario de elementos "reales" que aparecen en la fotografía. La denotación es un vaciado a una matriz descriptiva de información lo que cada foto trae consigo (lugares, objetos, personajes, etc.). La utilidad del análisis denotativo es que nos permite tener una primera aproximación al tipo de fotógrafo al cual nos estamos refiriendo, los temas principales que abordó, sus preocupaciones centrales, una primera organización temática y, por tanto, las características fundamentales de su obra. Sin embargo, este abordaje es limitado, por lo que es pertinente dar un paso hacia lo que Barthes llamará los códigos de connotación:

“En la fotografía, el mensaje denotado, al ser absolutamente analógico, es decir privado de un código, es además continuo y no tiene por objeto intentar hallar las unidades significantes del primer mensaje; por el contrario, el mensaje connotado comprende efectivamente un plano de la expresión y un plano del contenido, significantes y significados: obliga, por tanto, a un auténtico desciframiento" ${ }^{\prime 56}$.

56 BARTHES, Lo obvio y lo obtuso, p. 16. 


\section{El análisis connotativo}

Barthes sugiere un desciframiento de los principales códigos de connotación, pues las fotos en sí mismas tienen connotaciones estructurales, es decir, un conjunto de códigos susceptibles de ser leídos y entendidos por un colectivo particular que es quien recibe las imágenes. Los "códigos de connotación" son eficaces en una determinada cultura. Para que la connotación tenga sentido, debe ser leída por un sector social; el gesto, la forma o la técnica, evocará una connotación diferente de acuerdo al lugar desde donde se lo mire: "El código de connotación no es, verosímilmente, ni 'natural' ni 'artificial', sino histórico, o, si así lo preferimos 'cultural'; sus signos son gestos, actitudes, expresiones, colores o efectos dotados de ciertos sentidos en virtud de los usos de una determinada sociedad" ${ }^{\prime 57}$.

En la búsqueda de las principales unidades de significación, son seis los aspectos en los que hay que poner atención.

i. El trucaje. Es el proceso de reconstruir las fotos con nuevos elementos que permitan evocar otras cosas que van más allá de la propia fotografía y la "realidad", canalizando más bien el interés del fotógrafo ${ }^{58}$.

ii. Las poses. Toda cultura tiene una serie de poses que evocan determinadas aspectos preestablecidos; por ejemplo manos juntas evocan la oración,

57 "Gracias a su código de connotación, la lectura de la fotografía es siempre histórica; depende del 'saber' del lector, igual que si fuera una verdadera lengua, que sólo es inteligible para el que aprende sus signos" Ibid., p. 23-24.

58 Hay que decir que una buena parte del periodismo vio con mucha desconfianza esta práctica, incluso el manual de periódico español El País prohibía cualquier tipo de modificación a la foto. Cartier Breson, por su parte, también desconfía del uso de otros elementos que modifiquen las fotografías. En los últimos años, con la aparición del programa de computación Photoshop y las nuevas facilidades tecnológicas, ésta es una práctica expandida, con las consecuencias de la muerte de la fotografía, diría Mirzoeff. (MIRZOEFF Nicholas, Una introducción a la cultura visual, Ed. Paidos, Barcelona 2002). 
dirigir la mirada al cielo es la relación con la divinidad, etc..

iii. Objetos. Los objetos son portadores de "asociaciones de ideas", "remiten a significados claros, conocidos". ${ }^{59}$

iv. Fotogenia. Se trata del uso de técnicas particulares que permitan resaltar algunos elementos de la foto. Por ejemplo, el uso de la iluminación, la oscuridad, la profundidad de campo, etc..

v. Esteticismo. Es el proceso a través del cual el fotógrafo se encarga de retocar el producto final con objetivos comerciales, artísticos o políticos.

vi. Sintaxis. La sintaxis es el encadenamiento de distintas imágenes que, sólo en su lectura articulada y progresiva permite la comprensión. Es un conjunto de fotos que, en la serie, logran tener sentido.

Estos seis elementos deben ser tomados en cuenta a la hora de analizar una fotografía. Concluye Barthes que, para hallar el código de connotación, se debe: "aislar, inventariar y estructurar todos los elementos 'históricos' de la fotografía, todas las partes de la superficie fotográfica que extraen su propia discontinuidad de un cierto saber del lector o de su situación cultural, como se prefiera" ${ }^{\prime 6}$.

Estos elementos son, sin duda, de un valor importante para analizar la imagen. Sin embargo, siguiendo estas sugerencias, ¿habremos llegado al sentido mismo de la fotografía? ¿Luego de este análisis, se habrán descubierto las

59 BARTHES, Lo obvio y lo obtuso, p 19. Un buen ejemplo es el uso de la imagen que realiza el Subcomandante Marcos del EZLN, pues, en cada aparición pública, lleva consigo algún objeto particular: una máscara, capucha, pipa, balas cruzadas en el pecho, etc.

60 Ibid., p. 24. 
estructuras subyacentes de las fotos y, por tanto, su sentido final? Creemos que no. Por eso, se debe dar un paso adelante y aplicar el método de análisis estructural de contenido que nos permita escudriñar las estructuras simbólicas que están detrás de las fotografías y que, por tanto, nos dibuje el sistema de sentido que está implícito. Es decir, falta un paso más para poder dibujar el "mundo social fotográfico" del cual habíamos hablado en la reflexión teórica.

\section{Las estructuras de sentido y el análisis estructural}

Hemos dicho, en la primera parte, que el objetivo de nuestro enfoque era llegar a desvelar el mundo social fotografiado, es decir, el sistema de sentido que oculta una determinada propuesta fotográfica. La herramienta para ello será el análisis estructural de contenido, que pretende, precisamente a través de análisis de materiales concretos, encontrar los modelos culturales de determinados grupos sociales.

El análisis estructural propone que los materiales tienen estructuras mínimas de sentido (llamadas técnicamente códigos disyuntivos) que, en su combinación, aglomeración y complejidad, forman auténticos modelos culturales. Se parte de la idea fundamental de que "el sentido, la percepción, son el resultado -y están 'dentro' de las relaciones que constituyen los unos en función de los otros", es decir, que a partir del tipo de relación que se establece es que se forman estructuras subyacentes. Estas relaciones son de dos naturalezas: Por un lado, la disyunción (la contra definición) "la cual permite, al interior de un mismo género (totalidad), identificar ciertas cosas existentes y específicas, unas en relación con otras", que será graficada con " / " ; y, por otro lado, la asociación (la conjunción), "la cual coloca los elementos ya identificados por disyunciones, en relación 
con otros elementos, salidos a la vez de otras disyunciones, formando así la "red" y los "atributos" de "todos ellos"61, graficada con una barra "/ ".

Con los dos principios articulados, vemos que se pueden formar estructuras básicas o "redes" de sentido que, en su combinación, van conformando grandes estructuras de sentido, que finalmente desembocarán en modelos culturales y, por tanto, en mentalidades. Estas formas de ver el mundo se despliegan ya sea en la vida cotidiana, ya sea en los grandes momentos de decisiones o acciones del sujeto.

Así, las estructuras concentran las grandes tensiones en principales códigos de sentido que articulan ideas mayores, pero con tensiones similares. Es decir, hay grandes isotopías (iso=lugar; topos=lógico), lugares de sentido similar.

Para realizar un análisis estructural, se debe, en primera instancia, construir un corpus de materiales que sea lo suficientemente rico en códigos disyuntivos. No se trata de una cuestión de cantidad sino de calidad; una foto puede tener muchos elementos más que una decena. Lo importante es cuánto contenido trae en sí.

Una segunda tarea es comprobar que los materiales pertenezcan a un mismo estatuto teórico, es decir, que su naturaleza sea similar (mismo autor o período o lugar, etc.). No se debe juntar materiales provenientes de distintas fuentes para estudiar un mismo modelo cultural, pues se corre el riesgo de mezclar y confundir conclusiones.

Los procedimientos operativos sugeridos por Jean Pierre Hiernaux, para el análisis, son:

61 HIERNAUX Jean Pierre, “Analyse structurale...”, p. 112 
1. Inventariar, en el material observado, las unidades de sentido que, alrededor del asunto analizado, parecen solicitarse las unas a las otras.

2. Identificar las disyunciones elementales de cuyo seno cada una de estas unidades adquiere su sentido propio al demarcarse de lo que "no es ella" ("¿Qué es lo que es contradefinido en relación a qué? ¿Qué es el inverso de qué? ¿Cuáles son las parejas de contradefinciones?").

3. Verificar las asociaciones entre unidades y términos de una pareja de contradefiniciones y las otras (“¿Qué está asociado a qué? ¿Qué está colocado del mismo lado de qué?).

4. Haciendo esto, "remontando las líneas de asociación", extraer el grafo de la estructura global que constituye y distribuye el conjunto de las unidades según un modelo particular, que da sentido al segmento del material observado y que esboza, asimismo, el "modelo cultural" concernido ${ }^{62}$.

Una vez que se han dado los primeros pasos en la observación de los materiales y la extracción de los grafos, se deben aglomerar los códigos en los grandes planos de percepción. Por ejemplo, la dimensión temporal, espacial, actorial, etc.. Cuando se han dibujado las principales dimensiones de percepción, se puede comenzar a construir propiamente un modelo cultural haciendo intervenir, ordenadamente, el conglomerado de informaciones.

Vamos a un ejemplo concreto y analicemos la fotografía de Julio Cordero tomada alrededor de los años 30 en Bolivia. 


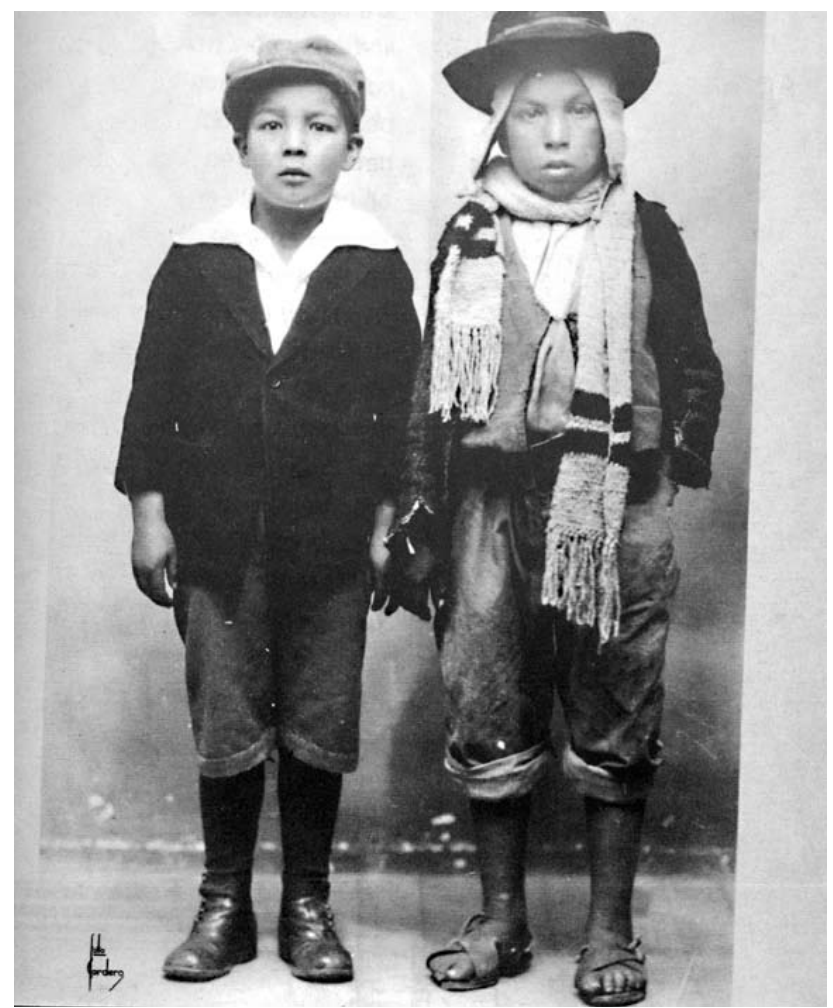

En esta fotografía, podemos ver que existen dos mundos contrarios compuestos por al menos 3 códigos disyuntivos:

\begin{tabular}{c}
\hline “tipo de niño" \\
\hline niño urbano / niño rural \\
\hline "Con qué se cubre la cabeza" \\
\hline boina / sombrero y lluchu \\
"Con qué se cubre el cuerpo" \\
\hline
\end{tabular}

traje, pantalón, camisa y saco / Vestido de bayeta, chaleco, chalina

$$
\text { "Qué se usa en los pies" }
$$

calcetines y zapatos / abarcas sin calcetines 
CÓMO DESCIFRAR SOCIOLÓGICAMENTE UNA FOTOGRAFÍA.

Elementos teórico-metodológicos

Hugo José Suárez

Esta sencilla imagen ya nos está ofreciendo la visión de dos mundos contrapuestos incluso en la niñez, cuyo eje principal de distinción es el vestido y que evoca la experiencia urbana vs. la rural. En este caso, la información con la que se cuenta hasta aquí no permite construir un modelo propiamente dicho, pero sí representa una base para, unida al análisis de otros materiales, explicar, por ejemplo, el modelo rural o urbano de los años 30 en Bolivia.

Pero, el análisis estructural propone que las posibilidades de combinación de códigos no se agotan en una estructura paralela. Existen, en el plano cognitivo, dos estructuras más: en abanico y cruzada.

Veamos la siguiente foto:

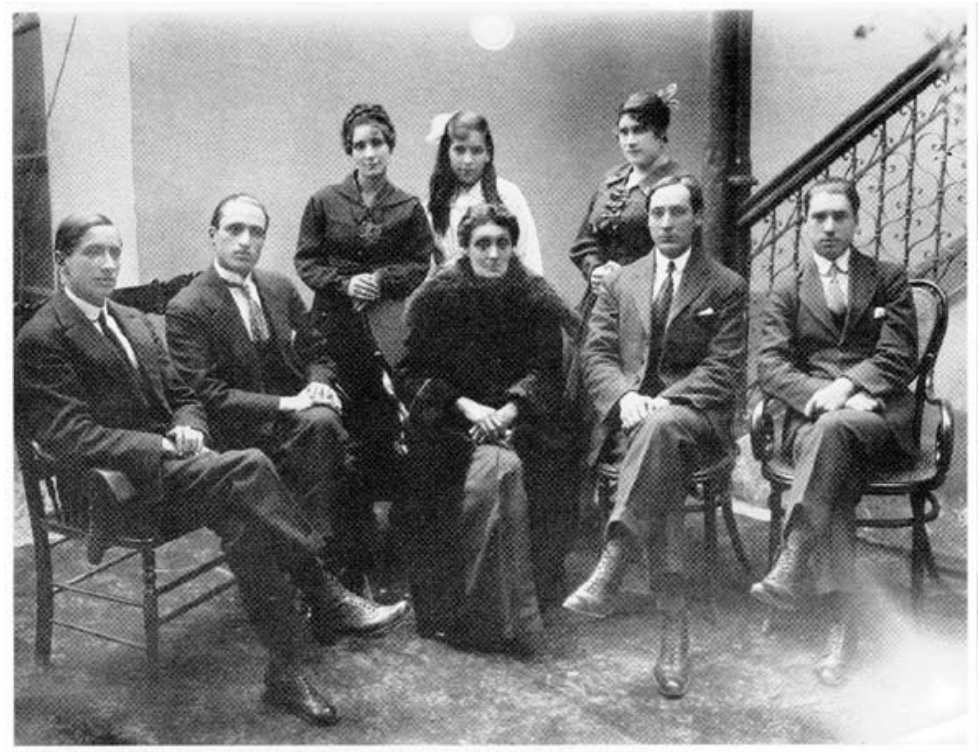

Luego del análisis de la imagen, se puede encontrar una estructura en abanico con tres códigos disyuntivos que forman la totalidad "familia" y que obedecen a una particular jerarquía: 


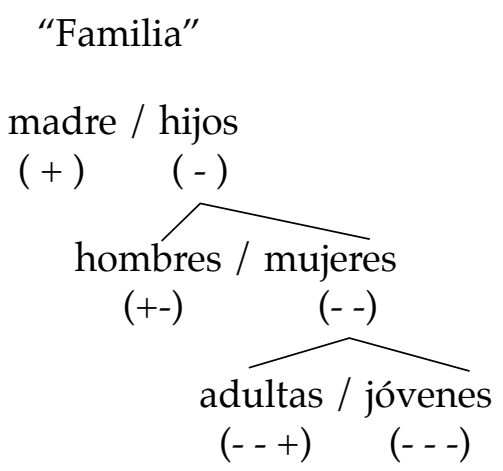

En la valoración evidente de este grafo, la madre aparece en el mejor sitial de la jerarquía familiar, mientras que las hijas jóvenes son las peor ubicadas. La administración del poder en el núcleo familiar aparecen retratadas con relativa claridad, mostrando cuánto valor tiene una jerarquía al interior de la familia y que, seguramente, se puede expandir a la organización de la sociedad.

Acudiendo a otras fotografías, podríamos encontrar nuevas estructuras (por razones de espacio no desarrollamos la estructura cruzada o el modelo actancial) que nos van dibujando, poco a poco, el mundo social del fotógrafo con las respectivas valoraciones, jerarquías y opciones del autor. Lo importante es que, al final del análisis, se podrá ver un modelo cultural que corresponderá a las características sociales de quien produjo el material fotográfico.

\section{Conclusiones}

Hemos empezado este documento con la intención de construir un dispositivo teórico - metodológico que nos permita acercarnos a la fotografía. Es decir, la pretensión ha sido construir sociológicamente una mirada de la imagen. Para ello, hemos acudido a autores clásicos y hemos tomado de ellos lo más útil para nuestros objetivos. 
CÓMO DESCIFRAR SOCIOLÓGICAMENTE UNA FOTOGRAFÍA.

Elementos teórico-metodológicos

Hugo José Suárez

A estas alturas, queda claro que la fotografía es un instrumento privilegiado de concentración de información social, que sometida a una serie de cuidadosas observaciones y, con un poco de malicia, como sugiere Goffman, puede mostrarnos sistemas simbólicos de determinados colectivos. La intención tendrá que ser mostrar el mundo social fotografiado de determinada propuesta, dejando ver en ella sus valoraciones, jerarquías y sentidos que están profundamente anclados en las imágenes.

Pero es evidente que ningún despliegue conceptual o propuesta metodológica tienen validez si no son eficaces para comprender y explicar la realidad social. Es por eso que estas reflexiones sólo podrán ser evaluadas a la hora de ser confrontadas con problemas empíricos y dar respuestas convincentes. Esa es la tarea que queda para una futura investigación ${ }^{63}$.

63 Véase nuestro trabajo de análisis empírico de fotografías: "Julio Cordero (19001920): fotógrafo del progreso en Bolivia" a ser publicado próximamente en la revista mexicana Relaciones. 